DOC.

D101,60/5:

99-07

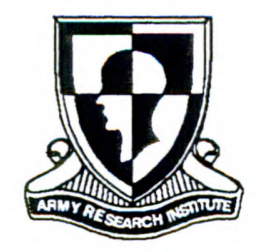

Research Product 99-07

\title{
Tacit Knowledge for Military Leaders: Platoon Leader Questionnaire
}

\author{
The Library of the \\ MAY 171999 \\ University of Illinois \\ at Urbana-Champaign
}

March 1999

Fort Leavenworth Research Unit

U.S. Army Research Institute for the Behavioral and Social Sciences

Approved for public release; distribution is unlimited. 